\title{
Occurrence of the digenean Cryptocotyle lingua in farmed Arctic charr Salvelinus alpinus and periwinkles Littorina littorea sampled close to charr farms in northern Norway
}

\author{
Roar Kristoffersen \\ Department of Aquatic Biology, Norwegian College of Fishery Science, University of Tromsö, Dramsveien 201B, \\ N-9000 Tromsö, Norway
}

\begin{abstract}
Occurrence of Cryptocotyle lingua rediae was recorded in periwinkle samples collected adjacent to 10 charr farms and at control sites 1 to $5 \mathrm{~km}$ from the farms. In 7 out of 10 localities the prevalence of infection was higher in the sample taken adjacent to the farm than in the control, and overall prevalence was $13.7 \%$ in periwinkles near the farms and $6.1 \%$ in snails from the control sites, a highly significant difference. Prevalences in periwinkles close to farms tended to increase with duration of farming at the site. The role of the final host, piscivorous birds, is considered. Samples of charr from 11 farms were investigated for visible black spots caused by encysted $C$. lingua metacercariae. No infected charr were recorded in the 2 land-based farms where seawater exposed to UV-light (photozone) was pumped to the tanks, whilst $83.2 \%$ of the fish exhibited black spots in the 9 farms where the charr were stocked in floating net cages in the sea. In most infected fish the C. lingua cysts were located only on the fins in relatively small numbers.
\end{abstract}

\section{INTRODUCTION}

The expanding commercial fish cage culture may affect the distribution of aquatic parasites in wild host populations, both on a broader zoogeographical scale, and locally near individual fish farms. Transportation of fish for stocking, often over considerable distances both within and between countries, increases the danger of introducing non-endemic parasite species into new host populations (Hoffman 1970, Sindermann 1974, Buchmann et al. 1987).

With regard to local effects, transmission of parasites with direct single-host life cycles is favoured by high host densities and associated stress factors (Esch et al. 1975, McVicar \& MacKenzie 1976, Anderson 1982). Since fish are normally held at high densities in commercial farms, it is hardly surprising that many protozoans, monogeneans and parasitic copepods often create health problems under these conditions (Sindermann 1987). Fish farms may serve as focal points for the parasites (McVicar \& MacKenzie 1976), but little is known about the dynamics and effects of parasite transmission from such focal points to wild host populations and vice versa.

Parasites with indirect life cycles may be less abundant in farmed than wild fish (MacKenzie et al. 1976) an effect of the restricted diet of cultured fish which consists almost exclusively of enriched dry food. However, many digeneans with multiple-host life cycles produce free-living stages which infect the hosts directly. Transmission of these parasites may, therefore, be favoured by high host densities, independent of the food of the hosts (Anderson et al. 1978, Anderson 1982).

The digenean Cryptocotyle lingua infects marine fish, the second intermediate host, as swimming cercariae that are released from infected specimens of the common periwinkle Littorina littorea, which is the first intermediate host (Stunkard 1930). Periwinkles are infected by eating $C$. lingua eggs in the droppings from the final host, piscivorous birds (Stunkard 1930). In Scotland, MacKenzie et al. (1976) found that infections of $C$. lingua metacercariae were heavier in cultivated plaice Pleuronectes platessa than in wild populations. 
At a seawater cage site in northern Norway, prevalence of infection with $C$. lingua was high in Arctic charr Salvelinus alpinus, and $13.3 \%$ of the larger periwinkles close to the cage site were infested (Kristoffersen 1988).

Since the immune response towards encysted Cryptocotyle lingua metacercariae results in unappealing black spots in the skin of the fish (Chapman \& Hunter 1954, Sindermann \& Rosenfield 1954a, b, McQueen et al. 1973), the parasite may be a potential aesthetic problem in the growing commercial mariculture of charr, cod Gadus morhua and flatfishes. In addition, pathogenic effects, blindness, mortality and reduced lipid content have been reported in fish following Cryptocotyle infections (Sindermann \& Rosenfield 1954a, b, Steele 1966, Mawdesley-Thomas \& Young 1967, MacKenzie 1968, Shchepkina 1981, Lauckner 1984).

In the present study the occurrence of Cryptocotyle Ingua in common periwinkles in northern Norway was recorded. Further, the present status of occurrence of C. lingua metacercariae in farmed Arctic charr was estimated. The hypothesis that fish farms may function as focal points for the life cycle of C. lingua was investigated, and the results discussed in relation to the role of the final hosts and the duration of fish farming at the investigated sites.

\section{MATERIALS AND METHODS}

Examination of periwinkles. During the period 28 July to 18 August 1988, periwinkles Littorina Jittorea were collected by hand in the tidal zone adjacent to 10 charr cage sites in Nordland and Troms counties, Norway (Fig. 1). The distance between the southernmost site $\left(67^{\circ} 06^{\prime} \mathrm{N}, 14^{\circ} 13^{\prime} \mathrm{E}\right)$ and the northernmost site $\left(69^{\circ}\right.$ $16^{\prime} \mathrm{N}, 18^{\circ} 00^{\prime} \mathrm{E}$ ) is $290 \mathrm{~km}$. Control samples were taken from 8 localities within a range of 1 to $5 \mathrm{~km}$ from the farms, the distance varying with topography and occurrence of snails. Two pairs of neighbouring farms (nos. 7 and 8 and nos. 10 and 11) were compared to common control sites (see Table 1). Seawater temperature was measured at each farm site (Table 1). Since prevalence of infection with Cryptocotyle lingua in periwinkles is known to increase with increasing snail size (James 1968a, Robson \& Williams 1970, Lauckner 1984, 1987. Matthews et al. 1985), the largest specimens were collected at each site. Immediately after collection, shell height of the periwinkles was measured to the nearest $0.1 \mathrm{~mm}$ using a slide caliper. Each snail was then examined for $C$. lingua infection by crushing the shell and slicing the digestive gland in seawater under a binocular microscope at $4 \times$ magnification. When found, rediae and cercariae were pipetted off and examined at

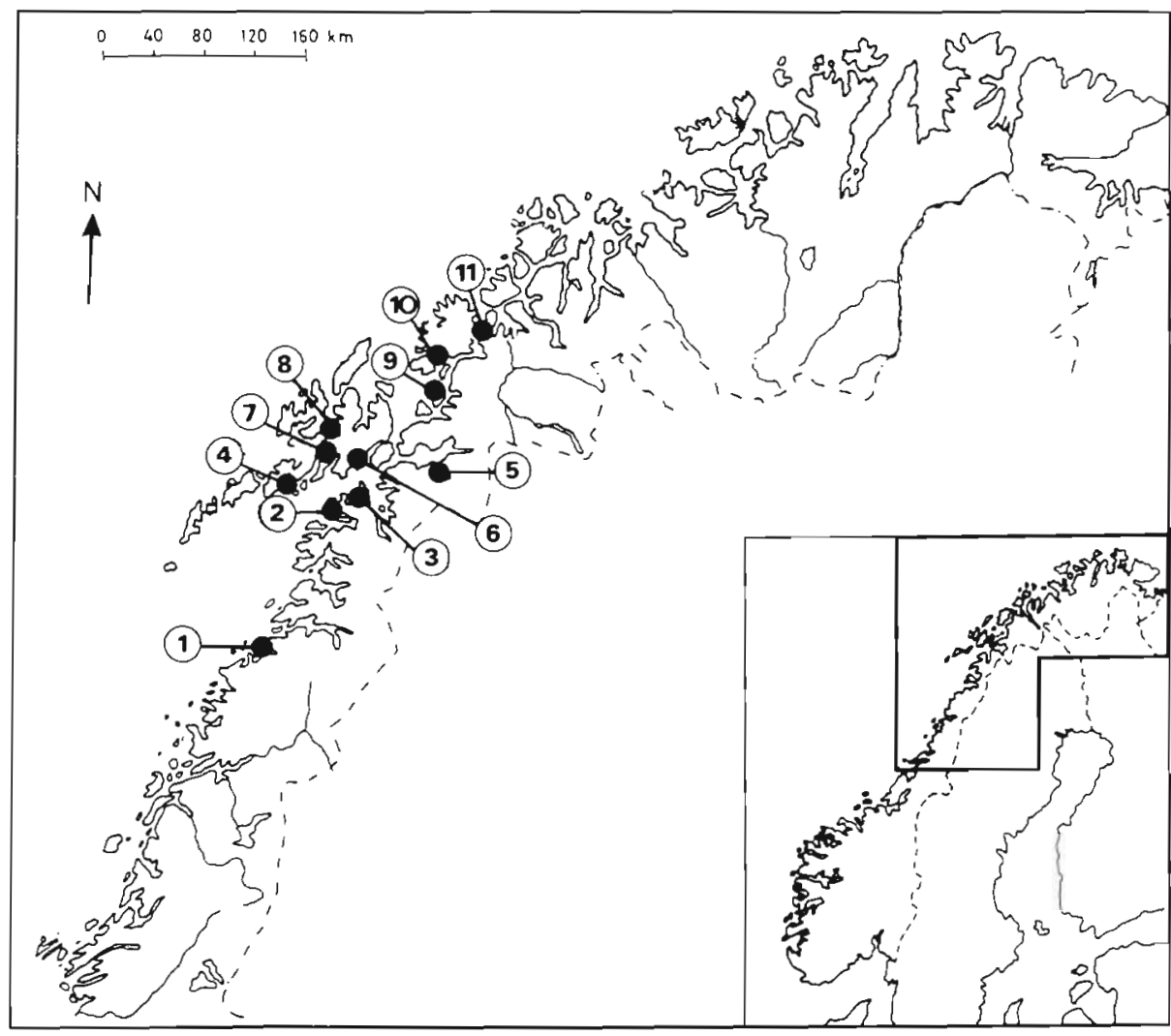

Fig. 1. Location of the study area, northern Norway. The examined localities are indicated by numbers 
Table 1 Littorina littorea. Mean shell height ( $\mathrm{mm}$ ) with $95 \%$ confidence intervals in the samples of periwinkles from each fish farm and the corresponding control. Numbers of examined snails at each site are indicated in parentheses; results from $t$-tests between mean shell heights from each locality are also given $\left({ }^{\cdots} p<0.01 ;{ }^{*} p<0.05\right.$; NS: no significant difference). Seawater temperatures at the farm sites at time of sampling are also listed

\begin{tabular}{|c|c|c|c|c|}
\hline Localitya & Farm & Control & $t$-test & $\begin{array}{c}\text { Temp } \\
\left({ }^{\circ} \mathrm{C}\right)\end{array}$ \\
\hline 1 & $25.3 \pm 1.2(40)$ & $20.1 \pm 0.7(40)$ & $\cdots$ & 8.0 \\
\hline 3 & $25.6 \pm 0.6(40)$ & $26.4 \pm 0.7(40)$ & NS & 14.2 \\
\hline 4 & $29.2 \pm 1.2(40)$ & $22.5 \pm 0.5(40)$ & $\cdots$ & 14.1 \\
\hline 5 & $20.4 \pm 0.5(38)$ & $19.0 \pm 0.6(33)$ & $\cdots$ & 14.0 \\
\hline 6 & $29.0 \pm 0.6(40)$ & $24.1 \pm 0.4(41)$ & $\cdot$ & 12.1 \\
\hline 7 & $24.2 \pm 0.6(40)$ & $25.8 \pm 0.8(40)^{\mathrm{b}}$ & $\cdot$ & 12.0 \\
\hline 8 & $26.1 \pm 0.6(40)$ & $25.8 \pm 0.8(40)^{b}$ & NS & 11.8 \\
\hline 9 & $25.9 \pm 1.0$ & $25.2 \pm 0.7(40)$ & NS & 13.8 \\
\hline 10 & $23.6 \pm 0.7(40)$ & $27.4 \pm 0.7(40)^{c}$ & $\cdots$ & 13.4 \\
\hline 11 & $20.4 \pm 0.6(40)$ & $27.4 \pm 0.7(40)^{c}$ & $\cdots$ & 13.8 \\
\hline
\end{tabular}

10 to $40 \times$ magnification. Rediae and cercariae were identified according to James (1968b).

Examination of farmed Arctic charr. During the same period as the periwinkle investigation, charr Salvelinus alpinus from 11 fish farms (Fig. 1) were examined for Crytocotyle lingua infection. At 9 farms the charr were held in floating net cages, and at 2 farms (nos. 2 and 4 ) the fish were stocked in tanks. The land-based farms treated the seawater pumped to the tanks with UV-light. At each farm a sample of charr was anaesthetised in chloro-butanol. Numbers of fish examined are shown in Fig. 4. The skin and fins of each fish were macroscopically examined. Fish that exhibited one or more of the typical black spots formed around dermal cysts of $C$. lingua were recorded as being 'infected', and individuals with no visible spots were recorded as 'uninfected'. This procedure provides minimum estimates of prevalence of infection, both because black spots are not formed around recently acquired parasites (McQueen et al. 1973), and because they are difficult to see on the dark dorsal surface of the charr. Fish noted as infected were divided into 2 groups, one consisting of lightly infected individuals with visible black spots located only on the fins. The other group had, in addition, one or more spots on the light ventral surface.

\section{RESULTS}

Infection with Cryptocotyle lingua rediae was recorded in all the samples of periwinkles, both those taken adjacent to the fish farms and those from the

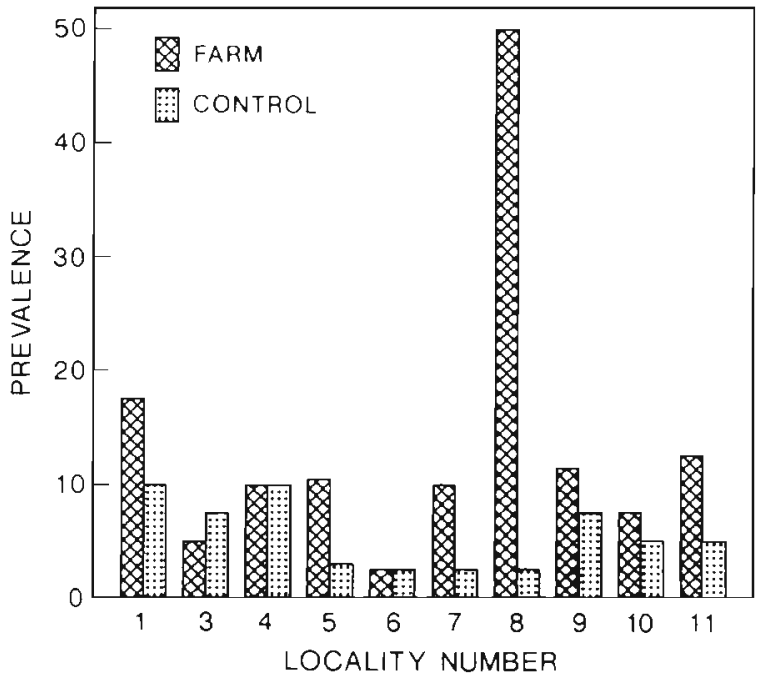

Fig. 2. Littorina littorea. Prevalence of Cryptocotyle lingua rediae in periwinkle samples from each charr farm and corresponding control site

control sites (Fig. 2). In snail samples taken adjacent to the farms, prevalence of infection varied between 2.5 and $50 \%$, while in the control samples the prevalence varied between 2.4 and $10 \%$.

In 7 out of 10 localities the prevalence was higher in the sample taken adjacent to the farm than in the control (Fig. 2). In 2 localities (nos. 4 and 6) prevalences of infection were equal, and in only 1 case was the higher prevalence recorded in the control sample (no. 3). Overall, prevalence was $13.7 \%$ in periwinkles collected adjacent to the farms and $6.1 \%$ in snails from the control sites. The difference was highly significant $\left(\chi^{2}=11.702\right.$, df $\left.=1, p<0.005\right)$.

Prevalence of infection is known to increase with increasing snail size, and in some instances significant differences were found between sizes of snails taken at the farm and control sites (Table 1). Snails from the farm sites were not, however, consistently larger than the controls. This was the case at 4 out of 10 localities (nos. 1, 4, 5 and 6), but at only 2 of these was the highest infection recorded by the farm. On the other hand, at 3 localities (nos, 7, 10 and 11) the mean shell height of the periwinkle sample was significantly larger at the control site. Nonetheless, the highest Cryptocotyle lingua infection was always recorded by the farm, and in the pooled material from these 3 localities the prevalence was over twice as high among the smaller snails adjacent to the farms $(10.0 \%)$ than among the larger specimens in the control samples $(4.2 \%)$. Further, at locality no. 8 , where snail size was equal in the farm and control samples, the infection with $C$. lingua was 20 times higher by the farm. Thus, differences in snail size between the 2 samples from. each locality may be rejected as the main reason for the observed pattern of higher infection by the farms. 


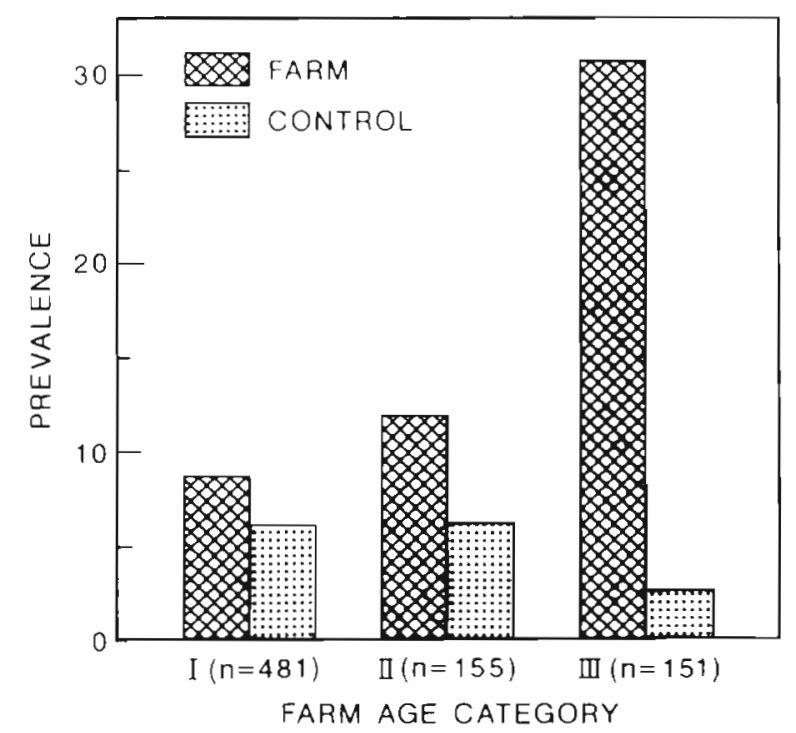

Fig. 3. Littorina littorea. Prevalence of Cryptocotyle lingua rediae in pooled periwinkle samples from different age categories of farms and corresponding control sites, where: category I = established under $3 \mathrm{yr}$; category II = established 3 to 5 yr; category III $=5$ yr or older

Cryptocotyle lingua infection in the periwinkle samples from the farms increased with the time the sites had been used for charr farming (Fig. 3). The difference was not significant between samples from farms in categories I (under $3 \mathrm{yr}$ ) and II ( 3 to $5 \mathrm{yr})\left(\alpha^{2}=\right.$ 0.668 , df $=1,0.5>p>0.1$ ). However, the proportion of infected snails collected adjacent to farms older than 5 yr (category III) was significantly larger than compared to farms in both category I and category II $\left(\chi^{2}\right.$ tests, $p<0.01$ ). A corresponding difference was not seen in the snail samples from the control sites (Fig. 3).

Infection with Cryptocotyle lingua metacercariae was recorded in all the charr samples taken from fish farms with floating sea cages, and the prevalence varied between 49 and $100 \%$ (Fig. 4). At farms mos. 2 and 4 , where the fish were held in tanks on land, no infected fish were recorded. The seawater intake to fish farm no. 2 was located in a shallow bay with a muddy bottom and brackish water where no periwinkles were found. At farm no. 4 snails infected with C. lingua were recorded on the rocky shore close to the seawater intake (Fig. 2). In the pooled material of charr from all 11 farms, the prevalence of infection with $C$. Iingua metacercariae was $68.5 \%$. If the 2 land-based farms are excluded, $83.2 \%$ of the charr reared in floating cages were infected, and $32.7 \%$ of the fish exhibited one or more black spots on the ventral surface. The highest occurrences of ventral surface spots were recorded at localities 7 and 8 , where the highest total prevalences of infection were also noted.

When the prevalences of Cryptocotyle ingua infection in the periwinkle and charr samples at each farm

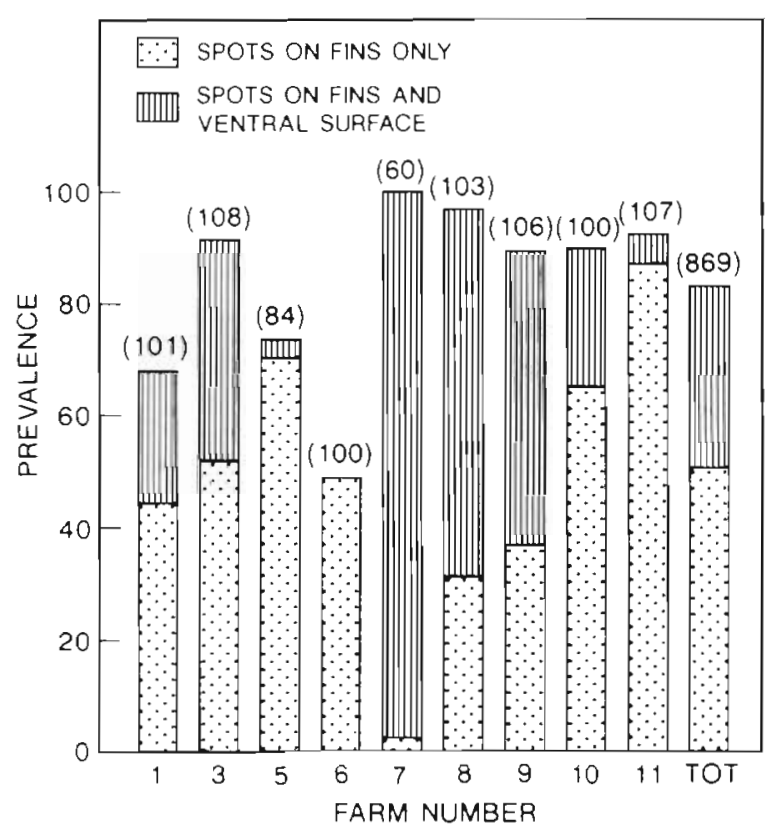

Fig. 4. Salvelinus alpinus. Occurrence of black spots caused by Cryptocotyle lingua infection in samples of charr at each farm and in the total material. The 2 land-based farms ( 2 and 4) are excluded from the figure since no infected fish were recorded here. Numbers of fish examined at each farm are indicated above the bars

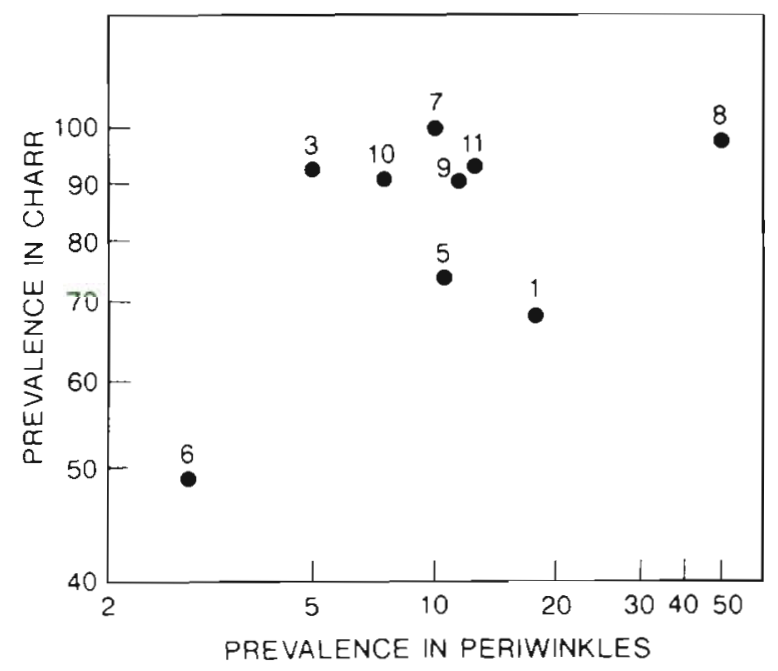

Fig. 5. Littorina littorea/Salvelinus alpinus. Prevalence of Cryptocotyle lingua infection in periwinkle and charr samples at each farm plotted on a log scale. Farm numbers are given at each point

were plotted on a log scale, no significant linear correlation was found $\left(\mathrm{r}=0.52, t_{\mathrm{d} 17}=2.01,0.1>\mathrm{p}>.05 \mathrm{i}\right.$ Fig. 5). Nevertheless, a general positive correlation appears to exist since the lowest prevalence in charr was recorded at the farm with the lowest prevalence in the periwinkle sample (farm no. 6), and, when the fraction of infected snails exceeded $5 \%$, the prevalence in the charr varied between 90 and $100 \%$ at most farms. 


\section{DISCUSSION}

Cryptocotyle lingua appears to be a common parasite in periwinkle populations along the coast of northern Norway since it was recorded at all the investigated locations. There were variations in incidence of infection among both the farm and control sites, and factors such as inter-tidal environmental conditions and differences in resistance among periwinkle strains may influence the abundance of $C$. lingua in snail hosts (Robson \& Williams 1970). There is, however, no reason to believe that such factors would have led to the higher levels of infection recorded in periwinkle populations collected adjacent to the fish farms in the current study. There were no obvious consistent topographic and/or physical differences between the farm and the control sites. It is also unlikely that mechanisms exist that would systematically lead to a higher resistance towards infection of $C$. lingua amongst snails at the control sites.

Several authors have concluded that the presence and behaviour of piscivorous birds have the most decisive impact upon the incidence of infection of Cryptocotyle lingua in periwinkle populations (Hoff 1941 , Sindermann \& Farrin 1962, Robson \& Williams 1970, Hughes \& Answer 1982, Irwin 1983, Mathews et al. 1985, Lauckner 1987). Although not quantified, quite large numbers of birds were observed in the vicinity of the farms during the current investigation. Gulls Larus spp. were most common, but crows Corvus corone, ravens $C$. corax and magpies Pica pica were also abundant. It is likely that farms, in contrast to control sites, attract birds which feed upon spilled dry pellets, fish offal and dead fish that are either floating in the cages, or are left exposed on the gangways or in open trash bins.

Bakke (1972) found that up to $63.9 \%$ of the examined common gulls Larus canus were infected with Cryptocotyle lingua in mid-Norway. Since the current results show that most of the farmed charr are infected with metacercariae of $C$. lingua, it is reasonable to believe that a large proportion of the local gulls carry the adult stage of the parasite. The incidence of C. lingua in birds needs further investigation, especially concerning the possible role of the Corvidae as final hosts. It is well established that the Laridae are important final hosts for C. lingua (Stunkard 1930, Bakke 1972).

A concentrated and high output of Cryptocotyle lingua eggs in the droppings of a relatively dense population of birds may be the key factor that explains the higher abundances of the parasite recorded in periwinkles collected close to the farms than in those collected at the control sites. The hypothesis of fish farms being focal points for the life-cycle of $C$. lingua is
Table 2. Littorina littorea. Mean shell height $(\mathrm{mm})$ with standard deviation of periwinkle samples from farms in the 3 different age categories. Results from $t$-tests between height distributions are also given $(\cdots p<0.001$; NS: no significant difference)

\begin{tabular}{|c|c|c|c|c|}
\hline $\begin{array}{l}\text { Farm } \\
\text { category }\end{array}$ & $\begin{array}{l}\text { Shell } \\
\text { height }\end{array}$ & SD & $\mathrm{n}$ & $t$-tests \\
\hline I & 26.1 & 3.448 & 240 & $\neg$ \\
\hline II & 23.0 & 3.543 & 75 & $=$ \\
\hline III & 23.3 & 3.324 & 78 & $\mathrm{NS}_{\mathrm{S}}$ \\
\hline
\end{tabular}

thus supported by the current results on infection in snails.

This conclusion is in accordance with results presented by Matthews et al. (1985). They found that infection rates of larval Digenea, including Cryptocotyle lingua, in gastropods declined away from the harbour of a small fishing port. It was suggested that this pattern was due to the increased concentration of definitive hosts, mainly seagulls, attracted to the harbour by dumping of raw fish offal. Likewise, Irwin (1983) found a higher level of $C$. lingua infection in gastropods near a sewer than in an unaffected locality nearby, and the author believed that this was a result of birds being attracted to the sewage outfall.

There were variations in the prevalences of Cryptocotyle lingua in the samples of periwinkles from the different farms. When the farms were classified according to age, there appeared to be a positive correlation between the length of time that the sites had been used for charr farming and the abundance of $C$. lingua in the snail samples. This could have merely been a reflection of size differences between periwinkles, in that the largest snails may have occurred in the samples from the oldest farms. However, a t-test of shell height distributions revealed that the periwinkles were significantly smaller close to the older than to the recently established farms (Table 2).

It seems therefore that the use of farm locations for several years resulted in an accumulation of infected individuals in the local periwinkle population, even though larval trematodes probably kill some large individuals each year (Lauckner 1987). In the laboratory it has been recorded that rediae of Cryptocolyte lingua can live and produce cercariae for at least $5 \mathrm{yr}$ in the snail host (Meyerhof \& Rothschild 1940). The results also suggest that the accumulation effect is restricted to the area in close proximity to the farms since there was no tendency towards an increasing prevalence of $C$. lingua infection in the control samples of increasing age.

Six of the 10 farms examined had been established either the same year or the year before the current 
investigation was carried out. Nevertheless the tendency towards higher infection in the pooled samples from the farms than at the control sites was also found at these new localities. This suggests that birds rapidly congregate at recently established farms, but there is also reason to believe that activities prior to fish culture had attracted final hosts to some sites. For example, the second highest prevalence of Cryptocotyle lingua in snails during the course of the study $(17.5 \%)$ was recorded at a location which had been used for charr farming for only 1 yr (farm no. 1). This site was previously used as a harbour for a fishing boat, and, hence, gulls had probably already been attracted to the locality by the prospect of a meal of fish offal. In addition, the rocky shore close to the farm seemed to be a nesting ground for gulls since several chicks were observed here. Hoff (1941) found much higher incidences of $C$. lingua in periwinkles near roosting and nesting sites of gulls than outside.

No infected charr were recorded at the 2 farms where the fish were stocked in tanks on land. At one of these (farm no. 4) Cryptocotyle lingua cercariae may have occurred in the seawater that was pumped to the rearing tanks, since infected snails were recorded close to the intake. However, the lack of fish infection suggests that the treatment of the seawater with UV-light probably killed the cercariae.

Most of the charr reared in floating sea cages exhibited black spots caused by encysted Cryptocolyte lingua metacercariae, but the visible $C$. lingua cysts were mainly located on the fins in relatively small numbers. Less than $1 / 3$ of the total fish material had spots on the white ventral surface, and generally only 1 to 5 cysts were seen here. Thus, the overall impression from the investigation is that the parasite does not constitute a serious problem for the marketing of farmed Arctic charr. It is also unlikely that the light infections recorded at the majority of farms would have any significant impact upon the health status of the fish.

However, at 2 farms the charr usually exhibited tens of black spots, and these results are more serious in terms of both marketing and possible health perspectives. One of these (farm no. 8) was the site that had been used for charr farming for the longest time, and the prevalence of Cryptocotyle lingua in the local periwinkle population was by far the highest recorded during the study. The fish at the other farm (no. 7) were purchased from farm no. 8, and may have become infected prior to the transfer.

Prevalences of Cryptocolyte lingua infection in the charr samples were generally high at the localities where snail infections were above $5 \%$, except for farms nos. 1 and 5. Here the values were well below those that should be expected on basis of the abun- dance of the parasite in the periwinkle samples. At farm no. 1 the charr cages were situated in brackish water of low temperature $\left(8^{\circ} \mathrm{C}\right)$. Production of $C$. In gua cercariae ceases when the temperature drops below 8 to $10^{\circ} \mathrm{C}$ (Sindermann \& Farrin 1962, Robson \& Williams 1970). Further, Möller (1978) demonstrated that both low temperatures and low salinities have a negative effect upon the development, infectivity and survival of the free-living stages (eggs and cercaria) of C. Lingua. Thus, it appears likely that the combination of these 2 factors at farm no. 1 resulted in a low infection rate of the charr. At farm no. 5, strong tidal currents occurred at the exposed farm site. This may have led to rapid dispersion and removal of $C$. lingua cercariae released from infected snails. Thus, the results from these 2 localities suggest that abiotic factors may have a significant impact upon the infection rate of farmed fish.

This study was restricted to the few commercial farms where charr is the stocked species. There is, however, little reason to believe that conditions are very different at the far more numerous salmon farms. In a sample of 30 salmon smolts examined at one of the charr farms (farm no. 5) in the current study, 20 fish $(66.7 \%)$ exhibited visible black spots. This probably means that the expansion of commercial mariculture along the Norwegian coast during the last couple of decades has created a large number of focal points for the life cycle of Cryptocotyle lingua, and the parasite may consequently have become more abundant in both periwinkle and bird populations.

Whether this has any significant impact upon the recruitment of wild inshore fish populations is at present an open question, although lethal effects caused by C. lingua infections in larval and juvenile marine fish are well documented (Sindermann \& Rosenfield 1954b, MacKenzie 1968, Lauckner 1984). Both from the commercial viewpoint of fish farmers, and with regard to wild fish populations, it appears desirable to implement efforts to prevent an increased abundance of the parasite. One step is to establish routines at the fish farms that prevent birds reaching dead fish or offal. In charr farming it is becoming clear that commercial rearing in brackish water gives best results, and this may be done in tanks on land or in closed floating cages. In both cases $C$. lingua cercariae can be prevented from reaching the fish.

Acknowledgements. Thanks to Anders Klemetsen and PerArne Amundsen for critical reading of the manuscript, and to Malcolm Jobling for comments and help with the text. Thanks also to Stig Skreslet for hospitality during the field work. The charr farmers are gratefully acknowledged for their help at the farms. This study was supported by the Norwegian Council for Fisheries Research (NFFR), Trondheim (Project number V401.034). 


\section{LITERATURE CITED}

Anderson, R. M. (1982). Epidemiology. In: Cox, F. E. G. (ed.) Modern parasitology. Blackwell Scientific Publications, London, p. 204-251

Anderson, R. M., Whitfield, P. J., Dobson, A. P. (1978). Experimental studies on infection dynamics: infection of the definitive host by the cercariae of Transversotrema patialense. Parasitology 77: 189-200

Bakke, T. A. (1972). Studies of the helminth fauna of Norway XXII: the common gull, Larus canus $\mathrm{L}$., as final host for Digenea (Platyhelminthes). I. The ecology of the common gull and the infection in relation to season and the gulls habitat, together with the distribution of the parasites in the intestine. Norw. J. Zool. 20: 165-188

Buchmann, K., Mellergaard, S., Köie, M. (1987). Pseudodactylogyrus infections in eel: a review. Dis. aquat. Org. 3: 51-57

Chapman, J. A., Hunter, G. W. (1954). Studies on host parasite reactions. VII. The pigment cells surrounding the metacercarial cysts of Cryptocotyle lingua in the cunner, Tautogolabrus adsperus (Walbaum). Trans. Am. Microsc. Soc. 73: 28-36

Esch, G. W., Gibbons, J. W., Bourque, J. E. (1975). An analysis of the relationship between stress and parasitism. Am Midl. Nat. 93: 339-353

Hoff, C. C. (1941). A case of correlation between infection of snail hosts with Cryptocotyle lingua and the habits of gulls J. Parasit. 27: 539

Hoffman, G. L. (1970). Intercontinental and transcontinental dissemination and transfaucation of fish parasites with emphasis on whirling disease (Myxosoma cerebralis). In Snieszko, S. F. (ed.) A Symposium on Diseases of Fishes and Shellfishes. Special Publication No. 5, American Fisheries Society, Washington, D.C., p. 69-81

Hughes, R. N., Answer, R. (1982). Growth, spawning and trematode infection of Littorina littorea (L.) from an exposed shore in North Wales. J. mollusc. Stud. 48: $321-330$

Irwin, S. W. B. (1983). Incidence of trematode parasites in two populations of Littorina saxatilis (Olivi) from the north shore of Belfast Lough. Ir. Nat. J. 21, 26--29

James, B. L. (1968a). The occurrence of larval Digenea in ten species of intertidal prosobranch molluscs in Cardigan Bay. J. nat. Hist. 2: 329-343

James, B. L. (1968b). The distribution and keys of species in the family Littorinidae and of their digenean parasites, in the region of Dale, Pembrokeshire. Field Studies 2: 615-650

Kristoffersen, R. (1988). A new species of parasite on Arctic charr, Salvelinus alpinus (L.), in seawater cages in Scandinavia. Aquaculture 71: 187-191

Lauckner, G. (1984). Impact of trematode parasitism on the fauna of a North Sea tidal flat. Helgoländer Meeresunters. 37: 185-199

Lauckner, G. (1987). Ecological effects of larval trematode infestation on littoral marine invertebrate populations. Int J. Parasitol. 17: 391-398

MacKenzie, K. (1968). Some parasites of 0-group plaice, Pleuronectes platessa L., under different environmental conditions. J. mar. Res. 3: 1-23

Responsible Subject Editor: O. Kinne, Oldendorf, Germany
MacKenzie, K., McVicar, A. H., Wadell, I. F. (1976). Some parasites of plaice Pleuronectes platessa L. in three different farm environments. Scott. Fish. Res. Rep. 4: 1-14

Matthews, P. M., Montgomery, W. I., Hanna, R. E. B. (1985) Infestation of littorinids by larval Digenea around a small fishing port. Parasitology 90: 277-287

Mawdesley-Thomas, L. E., Young, P. C. (1967). Cutaneous melanosis in a flounder (Platichthys flesus L. ). Vet. Rec. 81. 384-385

McQueen, A., MacKenzie, K., Roberts, R. J., Young, H. (1973). Studies on the skin of plaice (Pleuronectes platessa L. ). III The effect of temperature on the inflammatory response to the metacercariae of Cryptocotyle lingua (Creplin, 1825) (Digenea: Heterophyidae). J. Fish Biol. 5: 241-247

McVicar, A. H., MacKenzie, K. (1976). Effects of different systems of monoculture on marine fish parasites. In: Cherrett, J. M., Sagar, G. R. (ed.) Origins of pest, parasite, disease and weed problems. The 18th Symposium of The British Ecological Society Bangor, 12-14 April 1976. Blackwell Scientific Publications, London, p. 163-182

Meyerhof, E., Rothschild, M. (1940). A prolific trematode Nature, Lond. 146: 367

Möller, H. (1978). The effects of salinity and temperature on the development and survival of fish parasites. J. Fish Biol 12: $311-323$

Robson, E. M., Williams, I. C. (1970). Relationships of some species of Digenea with the marine prosobranch Littorina littorea (L.) I. The occurrence of larval Digenea in $L$. littorea on the North Yorkshire coast. J. Helminthol. 44 $153-168$

Shchepkina, A. M. (1981). The effect of Cryptocotyle concavum metacercariae on the lipid content of the tissue of Gobius melanostomus. Parazitologiya 15: 185-187. (In Russian; English summary)

Sindermann, C. J. (1974). Diagnosis and control of mariculture diseases in the United States. Nat. Mar. Fish. Serv. Tech. Ser. Rep. No. 2

Sindermann, C. J. (1987). Effects of parasites on fish populations: practical considerations. In: Howell, M. J. (ed.) Parasitology - quo vadit? Int. J. Parasit. 17(2). Pergamon Press, Oxford, p. 371-382

Sindermann, C. J., Rosenfield, A. (1954a). Diseases of fishes of the western North Atlantic. I. Diseases of the sea herring (Clupea harengus). Maine Dept. Sea Shore Fish. Res. Bull. 18: $1-23$

Sindermann, C. J., Rosenfield, A. (1954b). Diseases of fishes of the western North Atlantic. III. Mortalities of sea herring (Clupea harengus) caused by larval trematode invasion. Maine Dept. Sea Shore Fish. Res. Bull. 21 1-16

Sindermann, C. J., Farrin, A. F. (1962). Ecological studies of Cryptocotyle lingua (Trematoda: Heterophyidae) whose larvae cause 'pigment spots' of marine fish. Ecology 43 $69-75$

Steele, J. H. (1966). Experiments on 0-group plaice in underwater tanks. Comm. Meet. Int. Counc. Explor Sea C.M. ICES [Near Northern Seas Comm.] C9: 1-4

Stunkard, H. W. (1930). Life history of Cryptocotyle lingua (Creplin) with notes on the physiology of the metacercaria. J. Morphol. 50: 143-190

Manuscript first received: February 13, 1990 Revised version accepted: August 14, 1991 